\title{
Cross-national differences in happiness: Cultural measurement bias or effect of culture?
}

\author{
Ruut Veenhoven
}

\begin{abstract}
The number of cross-national research studies on happiness is soaring, but doubts about the comparability of happiness between countries remain. One source of doubt is the possibility of cultural measurement bias. Another source of doubt is in the theory that happiness is culturally relative. These qualms were checked using the available data on differences in average happiness across nations. It appears that happiness can be compared across nations and used as an indicator of how well people thrive in a society.
\end{abstract}

Keywords: happiness, life-satisfaction, cross-cultural, cultural measurement bias

\section{Introduction ${ }^{1}$}

Happiness is a main goal in modern society; most individuals reach out for a happy life and as a citizen typically they endorse policies that aim at greater happiness for a greater number. Consequently, there is a rising demand for knowledge about happiness.

Policy makers are particularly interested in societal conditions that promote happiness and the research field of comparative research into happiness in nations is one of the responses to this interest. This strand of research started in the early 1960s with Cantril's (1965) seminal book, The Pattern of Human Concerns. Forty years on comparative research into happiness has developed into a major research field and survey studies on happiness have been done in almost every country in the world. To date (March 2012) some 4500 survey findings on happiness in nations are available in the World Database of Happiness (Veenhoven, 2012b), which have been used in some 500 scientific publications on happiness and society (Veenhoven, 2012c).

Yet, although the number of comparative research studies on happiness is soaring, there are still doubts about the validity of the reported results. One misgiving is whether happiness can be meaningfully compared across nations, given that measures are likely to be subject to cultural bias. Another qualm is that happiness draws on cultural variable notions of the good life and that any research aiming at universal conditions for happiness is therefore pointless. In this paper these reservations are considered in the light of what we have learned in the last forty years.

${ }^{1}$ Shortened version of a paper presented at the conference: Happiness: Does culture matter? Berlin, November 2011. 


\section{Practice of comparative happiness research}

In order to know what we are talking about, I will first define happiness. Next I will consider acceptable measures of this concept and summarize the main findings obtained using these measures in cross-national research.

\subsection{Concept of happiness}

The word 'happiness' is used in various ways. In the widest sense it is an umbrella term for all that is good. In this meaning it is used interchangeably with terms like 'wellbeing' or 'quality of life' and denotes both individual and social welfare. The word is also used more specifically to denote subjective appreciation of life and that is the meaning addressed in this paper. I define happiness as the degree to which an individual judges the overall quality of his/her own life-as-a-whole favorably. In other words: how much one likes the life one leads. This definition is explained in more detail in Veenhoven (1984: 22-25; 2000).

\subsection{Measurement of happiness}

Defined as the subjective satisfaction with one's life-as-a-whole, happiness is something that we have in mind and things we have in mind can be measured using questioning. Questions on happiness can be posed in different ways, directly or indirectly, and using single or multiple items.

Indirect questioning using multiple items is quite common in psychological measurement and for that reason the first generation of happiness measures consisted mainly of 'inventories', such as the 20-item Life Satisfaction Index of Neugarten et al. (1961). This approach is appropriate for assessing fuzzy mental syndromes of which the individual is not necessarily aware, such as 'alienation' or 'neuroticism'; one cannot ask respondents how alienated they are. Yet in the case of happiness, the concept is clear-cut and respondents are aware by definition. Hence happiness can also be measured using single direct questions. ${ }^{2}$

\subsubsection{Common questions}

Some common questions are presented in Box 1 (below). All of the questions on happiness that have ever been used in empirical studies are collated and available in the collection Measures of Happiness of the World Database of Happiness (Veenhoven, 2012c). ${ }^{3}$

\subsubsection{Validity}

Critics have suggested that responses to questions on happiness actually measure other phenomena. Rather than indicating how much respondents enjoy life, the answers will reflect their normative notions and desires. I have checked these qualms elsewhere and did not find empirical support for any of them (Veenhoven, 1984: 3/1). Later reviews of the evidence also concluded that questions about satisfaction with life are typically well understood and properly

\footnotetext{
${ }^{2}$ A disadvantage of single questions is their vulnerability to slight variations in wording. Such variations balance out when multiple questions are used. Yet a common disadvantage of multiple questions is that wrong items slip in. For instance, of the 20 items in Neugarten's Life Satisfaction Index only some tap happiness as defined here. Most of the other items concern, rather, conditions for happiness, such as social participation.

${ }^{3}$ The collection 'Measures of Happiness' is limited to indicators that fit the concept as defined here. This fit is established on the basis of face-validity; does the question(s) really concern subjective enjoyment of one's life-as-awhole? Questions that address slightly different matters are not included. Consequently, the observations obtained using these questions are not incorporated in the finding collections of the World Database of Happiness.
} 
answered (e.g. Diener, 1994; Lucas et al., 1996; Helliwell \& Wang, 2012). In short, direct questions on happiness measure what they are supposed to measure.

\section{Box 1. Some currently used survey questions on happiness}

\section{Single questions:}

"Taking all together, how happy would you say you are: very happy, quite happy, not very happy, not at all happy?" (Standard item in the World Value Studies)

"How satisfied are you with the life you lead? Very satisfied, fairly satisfied, not very satisfied, not at all satisfied?" (Standard item in Euro-barometer surveys)

"Here is a picture of a ladder. Suppose the top of the ladder represents the best possible life for you and the bottom of the ladder the worst possible life. Where on the ladder do you feel you personally stand at the present time?" (0-10 ladder-like rating scale) (Cantril's, 1965 present life ladder rating)

\section{Multiple questions (summed):}

Same question asked twice: at the beginning and at the end of interview.

"How do you feel about your life-as-a-whole? Delighted, pleased, mostly satisfying, mixed, mostly dissatisfying, unhappy, terrible?" (Andrews \& Withey, 1976: Life 3)

Five questions, rated on a 1-7 scale ranging from strongly agree to strongly disagree. (Diener, 1985 Satisfaction With Life Scale (SWLS)):

1) In most ways my life is close to ideal

2) The conditions of my life are excellent

3) I am satisfied with my life

4) So far I have gotten the important things I want in life

5) If I could live my life over, I would change almost nothing. ${ }^{4}$

\subsubsection{Reliability}

Although single questions on happiness seem to measure what they are supposed to measure, they measure it rather imprecisely. When the same question is asked twice in an interview, the responses are not always identical, with correlations of about +.70 . Over a period of a week, test-retest reliability drops to circa +.60 .5 Though responses seldom change from 'happy' to 'unhappy', switches between 'very' and 'fairly' are rather common. The difference between response-options is often ambiguous and the respondents' notion about their happiness tends to be general. Thus any choice for one answer-category or another is sometimes haphazard.

Because choice is often uncertain, subtle differences in interrogation can exert considerable effect. Variations in the place where the interview is held, characteristics of the interviewer, the

\footnotetext{
${ }^{4}$ In my view this last item is not appropriate. One can be quite satisfied with life, but still be open to the opportunity to try something else.

${ }^{5}$ World Database of Happiness, Correlational findings (Veenhoven 2012g), Subject section 'Happiness career: Recent happiness' (H5.2.1.1).
} 
sequence of questions and precise wording of the key item can tip the scale to one response or the other. Such effects can occur in different phases of the response process, during consideration of the answer and in how the judgment is communicated. Much of these biases are random, and balance out in large samples. Unless systematic bias is involved, this is no great problem in comparing average happiness across nations. In sum, responses to questions on happiness are not very precise, but this is no real problem in assessment of average happiness in nations.

\section{Cross-national pattern of happiness}

The above-mentioned questions on happiness have been used in survey studies among the general population in many nations. The first survey of this kind was done in the USA in 1946. To date, survey findings on happiness are available for almost all the nations of the world. All the findings are gathered in the collection Happiness in Nations (Veenhoven, 2012b) of the World Database of Happiness. The most commonly used question reads:

“Taking all together, how satisfied or dissatisfied are you with your life as a whole these days?"

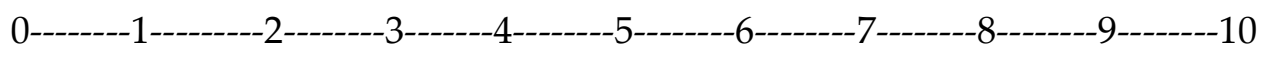

Dissatisfied

Satisfied

An example of the distribution of responses is presented in Figure 1. This is the case for Germany in 2006, where the average score was 7.2.

Figure 1. Happiness in Germany in 2006

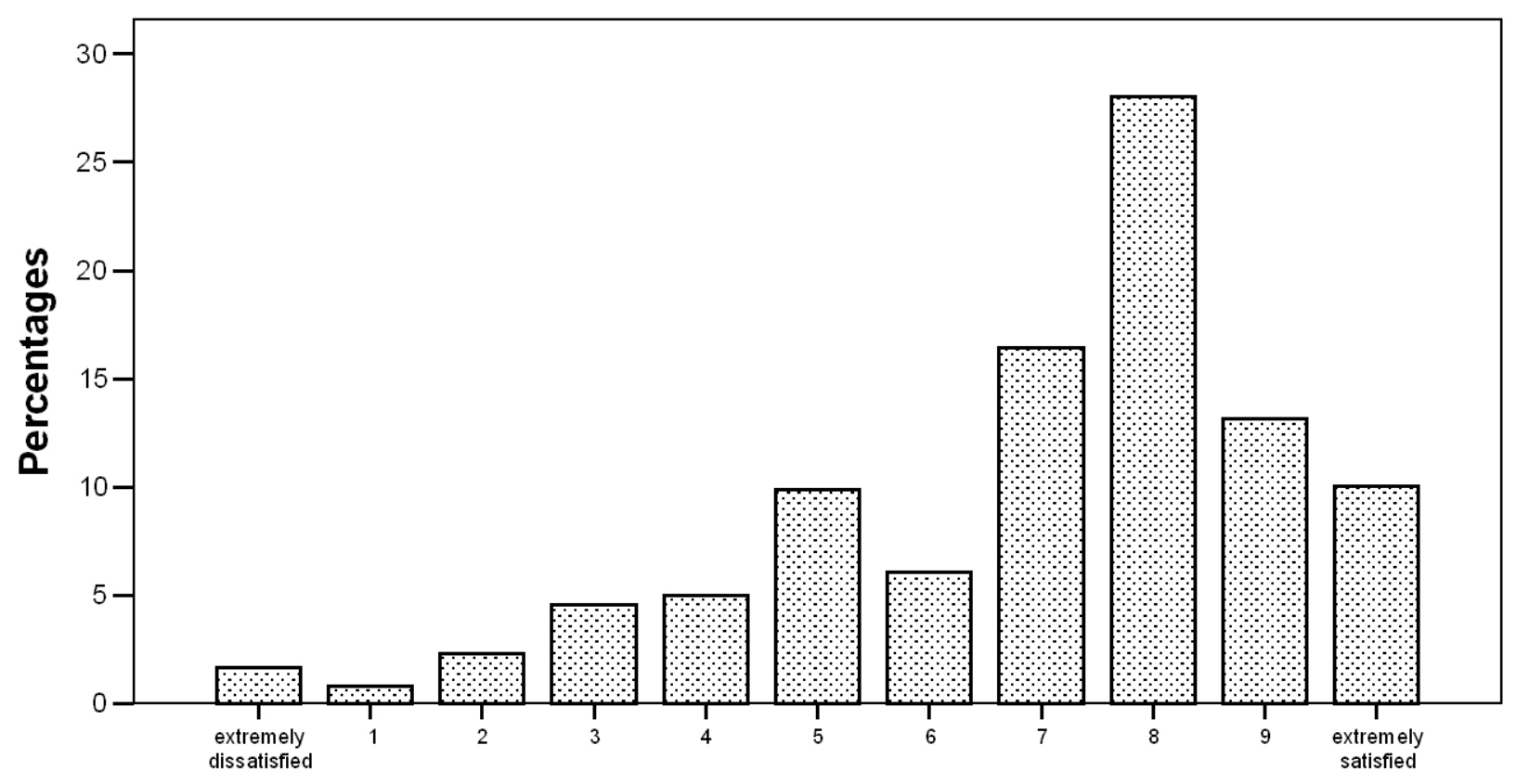

Source: European Social Survey (2006).

\section{Life satisfaction}




\subsection{Differences in average happiness across nations}

Responses differ widely across nations. Some illustrative results are presented in Table 1 (below). It may be no surprise to see four West European nations in the top five, though one might not have expected average values as high as 8 . The top position of Costa Rica ${ }^{6}$ may be more of a surprise, yet Mexico is also among the happiest countries. Average happiness is higher than one would expect in all Latin American nations, while happiness is lower than common expectation in industrialized Asian nations, e.g. only 6.3 in China and 6.5 in Japan.

Table 1. Average happiness (0-10) in Nations 2000-2009

\begin{tabular}{|c|c|c|c|c|c|}
\hline \multicolumn{2}{|l|}{$\begin{array}{r}\text { Top } \\
>7.8\end{array}$} & \multicolumn{2}{|c|}{$\begin{array}{c}\text { Middle range } \\
6-5\end{array}$} & \multicolumn{2}{|c|}{$\begin{array}{c}\text { Bottom } \\
<3.6\end{array}$} \\
\hline Costa Rica & 8.5 & South Korea & 6.0 & Sierra Leone & 3.5 \\
\hline Denmark & 8.3 & South Africa & 5.8 & $\begin{array}{l}\text { Benin, } \\
\text { Zimbabwe }\end{array}$ & 3.0 \\
\hline Iceland & 8.2 & Russia & 5.5 & Burundi & 2.9 \\
\hline Switzerland & 8.0 & Ghana & 5.2 & Tanzania & 2.8 \\
\hline $\begin{array}{l}\text { Finland, Mexico, } \\
\text { Norway }\end{array}$ & 7.9 & Pakistan & 5.0 & Togo & 2.6 \\
\hline
\end{tabular}

Source: Veenhoven (2012d).

\subsection{Change in average happiness over time}

Though it is commonly assumed that we do not get any happier (Easterlin, 1974), the available data show that average happiness has increased in most modern nations over the last 40 years. See Table 2 (below). Note that Denmark is among the countries where happiness has increased. The Danes were already quite happy in the 1970s and have gained about half a point on the 010 scale since. This means that even greater gains are possible in other nations.

\subsection{Societal correlates of happiness}

The observed differences in average happiness across nations are not unsystematic but go hand in hand with variation in several societal characteristics. Some of these are presented in Table 3 (below). Much of the above-mentioned correlates of average happiness are part of the 'modernity' syndrome. Hence, similar patterns emerge if we consider further indicators of modernity, such as urbanization, industrialization, informatisation and individualization. The more modern the country, the happier its citizens are. This finding will be a surprise to prophets of doom, who associate modernity with anomie and alienation. Though modernization may involve problems, ${ }^{7}$ its benefits are clearly greater (Veenhoven, 2005).

\footnotetext{
${ }^{6}$ The score of 8.5 in Costa Rica is based on only one survey in 2007, while the averages for most other nations are based on several surveys over the years 2000 to 2009.

${ }^{7}$ One of the problems of modernization is that the change from traditional society to the modern pattern involves social costs, which temporarily offsets the benefits of modern society. This pattern was observed in Western Europe when industrialisation took off and recently also in Eastern Europe between 1990-2010, where happiness followed a $\mathrm{V}$-pattern after the transformation that followed the fall of communism. The stagnant happiness in Japan and the delayed rise of happiness in South Korea can be explained in this vein.
} 
Table 2. Change in average happiness in nations 1970-2010

\begin{tabular}{|c|c|c|c|c|c|}
\hline \multicolumn{2}{|c|}{$\begin{array}{c}\text { Up } \\
\text { significant increase }\end{array}$} & \multicolumn{2}{|c|}{$\begin{array}{c}\text { Stable } \\
\text { no significant change }{ }^{8}\end{array}$} & \multicolumn{2}{|c|}{$\begin{array}{c}\text { Down } \\
\text { significant decrease }\end{array}$} \\
\hline Italy & +0.63 & Spain & +0.29 & Portugal & -0.68 \\
\hline Denmark & +0.55 & Japan & +0.20 & & \\
\hline France & +0.55 & Ireland & +0.19 & & \\
\hline Luxemburg & +0.41 & West Germany & 0.00 & & \\
\hline USA & +0.29 & Greece & -0.30 & & \\
\hline UK & +0.26 & Belgium & -0.33 & & \\
\hline Netherlands & +0.26 & & & & \\
\hline
\end{tabular}

Source: Veenhoven (2012e).

Table 3. Happiness and society in 146 Nations around 2006

\begin{tabular}{lcc}
\hline Characteristics of society & Correlation with happiness & $N$ \\
\hline Affluence & +.69 & 136 \\
Rule of law & & \\
Civil rights & +.50 & 131 \\
Corruption & -.69 & 137 \\
Freedom & & \\
Economic & +.63 & 135 \\
Political & +.53 & 131 \\
Personal & +.41 & 83 \\
Equality & & \\
Income inequality & -.08 & 119 \\
Gender inequality & -.21 & 110 \\
Pluriformity & & 126 \\
\% Migrants & & 77 \\
Tolerance of minorities & +.29 & \\
Modernity & +.49 & 138 \\
Schooling & & 137 \\
Urbanization & +.56 & \\
Explained variance (Adjusted $\mathrm{R}^{2}$ ) & +.58 & \\
\hline
\end{tabular}

Source: Veenhoven (2012f).

\footnotetext{
${ }^{8}$ The values for Spain and Greece do not reach the level of significance because they are based on less data points. The values for Belgium do not reach the level of significance because of the high levels of fluctuation in the data they are based on.
} 


\section{Reality value of the differences: Some validity tests}

What do these differences mean? Is life really more enjoyable in modern nations such as Denmark than in 'underdeveloped' nations such as Togo? Or are the differences due to cultural measurement error? Below I will check the validity of these differences in two ways; first I will consider the evidence for some specific distortions and next I will report some global validity checks.

\subsection{Tests of specific distortions}

Several suggestions have been made about possible sources of measurement distortion. The first is that translation plays us false, since words like 'happiness' and 'satisfaction' have subtly different connotations in various languages. Similar questions would therefore measure different matters. A second suggestion is that responses are systematically distorted by desirability bias. In countries where happiness ranks high as a value, people will be more inclined to overstate their appreciation of life. A third claim is that response styles distort the picture. It is suggested that in collectivist societies people tend to present themselves as 'average', which leads to lower happiness scores. Finally, a common suggestion is that happiness is a typical Western concept. Unfamiliarity with the concept in non-western cultures is seen to result in low ratings. I will inspect these claims one by one below.

\subsubsection{Differences a matter of language?}

The first claim is that the differences in reported happiness between countries result largely from variations in the meaning of key terms used in questions in different languages. Translations can be imprecise. Consequently, seemingly identical questions will tap different things.

If this claim is true we can expect the following: One: the pattern of difference must vary with the keyword used, countries that score high on a question that uses the word 'happiness' can rank low on questions that refer to 'satisfaction' with life, or score middle on a rating between 'best/worst' possible life. Two: in bi-lingual countries, ratings of happiness must differ between linguistic categories. Ratings must be more close to same-language populations abroad, than to different-language compatriots. Three: average happiness must be highly similar in nations where the same language is spoken, even if these nations differ considerably in other respects.

Keyword does not matter. Prediction one can be checked by comparing the happiness rank orders of countries on different happiness questions. For this purpose the Gallup/Kettering world survey (Gallup, 1976) was used. This cross-national study involves three questions on happiness that were posed in 11 mono-lingual nations. Data are presented in Table 4 (below) that show that the rank order of happiness is largely the same for all three questions. Though there are some minor differences, high positive rank order correlations emerge. Rank order correlations may over-emphasize slight differences between countries at the same level of happiness. Therefore, we also computed product moment correlations (r). These are respectively +.88 (Best/Worst by Happy), +.89 (Happy by Satisfied) and +.99 (Best/Worst by Satisfied). One could interpret these data as showing that the word 'happy' is less easily used in Germanic languages. Germany ranks relatively low on the happiness item, however, this is not a general pattern in languages of German origin. The difference does not appear in the results of the World Value Studies in 1980 and 1990, in particular not when the Netherlands and 
Iceland are considered. The data do not support the common idea that having the English language involves easier use of the term 'happy'.

Table 4. Happiness rank order of Nations on three survey questions: 11 Nations circa 1975

\begin{tabular}{|c|c|c|c|}
\hline \multirow[t]{2}{*}{ Country } & \multicolumn{3}{|c|}{ Happiness question } \\
\hline & happiness-in-life & satisfaction-with-life & best/worst possible life \\
\hline Australia & $2 / 3 / 4$ & 1 & $1 / 2$ \\
\hline Canada & 1 & 2 & $1 / 2$ \\
\hline Britain & $2 / 3 / 4$ & 4 & 3 \\
\hline USA & $2 / 3 / 4$ & 3 & 4 \\
\hline Brazil & 5 & 6 & 7 \\
\hline France & 6 & 7 & 8 \\
\hline W. Germany & 7 & 5 & 5 \\
\hline Mexico & 8 & 8 & 6 \\
\hline Japan & 9 & 10 & 9 \\
\hline Italy & 10 & 9 & 10 \\
\hline India & 11 & 11 & 11 \\
\hline rank order & \multicolumn{3}{|c|}{ 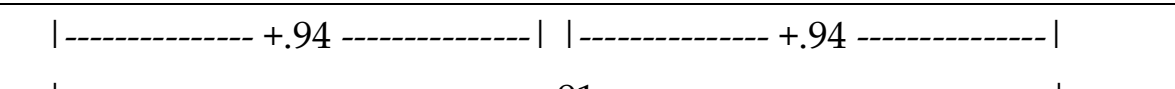 } \\
\hline correlation (rs) & \multicolumn{3}{|c|}{ 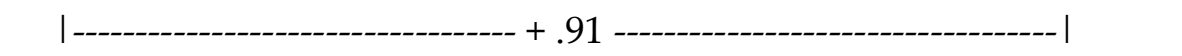 } \\
\hline
\end{tabular}

Source: Veenhoven (2012b).

Little difference in bi-lingual nations. Prediction two can be tested on two cases: Belgium and Canada. In Belgium two languages are spoken, French and Dutch. These linguistic categories can be identified in the data of the Eurobarometer surveys, which allow a specification of regions within the country. The scores can be compared with those of France and the Netherlands, which are also involved in the Eurobarometer survey. In Canada, French and English are spoken. Data on level of happiness in these categories are available from Blishen and Atkinson (1980). These scores can be compared with those for France and Britain from the Gallup/Kettering world survey (Gallup, 1976).

Results presented in Box 2 (below) show slight support for the prediction in the case of Belgium. French-speaking Belgians report somewhat less happiness than their Dutch-speaking compatriots. This difference is in the same direction as the, much greater, difference in average happiness between France and the Netherlands. The case of Canada is contrary to the prediction however. French Canadians report themselves slightly happier than Englishspeaking Canadians, while average happiness in France is markedly lower than that of the English speaking nations. Inglehart (1977) reports similar results in the case of Switzerland. The Swiss of all tongues report relatively high levels of satisfaction with life. Their scores rank far above the Germans, French and Italians, with whom the Swiss share their languages. Also, in this case the differences between language groups within the country are smaller than the differences in average happiness with the neighboring countries.

Sizable differences in average happiness in same-language nations. Prediction three can be checked by comparing English-language nations (Britain, Australia, Canada, USA), Portuguese-language nations (Portugal, Brazil), Spanish-language nations (Spain, Mexico) and German-language nations (former East Germany and West Germany). Data are presented in Table 5 (below). 
Box 2. Happiness of language groups in bi-lingual Nations compared to happiness in neighboring countries with the same language

Question: "On the whole, are you very satisfied (4), fairly satisfied (3), not very satisfied (2), or not at all satisfied (1) with the life you lead?"

Belgium

French speaking

France

Dutch speaking

Holland

3.3

Question: "All things considered, how satisfied or dissatisfied are you with your life as a whole? Which number comes closest to how you feel?" The respondent was asked to choose a number from a card containing an 11-point scale ranging from 1 to 11.

Canada

French speaking

8.9

France

7.6

English speaking

8.6

UK

8.5

USA

8.6

Source: Veenhoven (2012b: Table 1.2.1b and 1.2.2.b).

Linguistic categories: Belgium: Inglehart (1977: 160/2), Canada: Blishen et al. (1980: 33).

Table 5. Happiness in Nations where the same language is spoken

\begin{tabular}{ll}
\hline English & \\
Australia & 7.7 \\
Canada & 7.8 \\
UK & 7.1 \\
USA & 7.4 \\
& \\
German & \\
East Germany & 6.5 \\
West Germany & 7.0 \\
& \\
Portuguese & \\
Brazil & 7.5 \\
Portugal & 5.7 \\
& \\
Spanish & \\
Mexico & 7.9 \\
Peru & 6.2 \\
Spain & 7.2 \\
\hline
\end{tabular}

Source: Veenhoven (2012b).

Average happiness appears to be quite similar in the English-speaking nations, though not identical, with the UK lagging behind. A comparison of happiness in Portugal and Brazil shows greater happiness in the latter nation. Likewise, happiness is higher in Mexico than in sametongued Spain. The case of East and West Germany also shows similar sizable differences in 
average happiness in nations of the same language. This difference was even more pronounced in the first years after the re-unification of Germany, when living conditions still differed markedly between East and West Germany. Average happiness was about one point lower in East Germany than in West Germany at that time.

In sum, language cannot explain all the observed differences in average happiness across nations. If involved at all, the effect is modest at best.

\subsubsection{Differences a matter of desirability bias?}

The second claim to be tested is that part of the difference in self-reported happiness between countries results from differences in moral appreciation of happiness. In countries where happiness is regarded as morally desirable, people would be apt to over-report their satisfaction with life, both for reasons of ego-defense and social presentation. This claim is often raised to discount the high level of reported happiness in the USA (e.g. by Ostroot \& Snyder 1985).

Happiness is indeed more valued in happy countries, ${ }^{9}$ but this does not mean that reports of happiness in these countries are inflated by desirability bias. Moral acceptance of happiness is one of the cultural conditions for happiness and the degree of happiness is not without consequences for its evaluation. One of the ways to deal with chronic unhappiness is to denounce happiness as unimportant.

Strong correlation between global happiness and affect balance across nations. This distortion will manifest more pronouncedly in a difference in responses to questions about 'general life satisfaction' than in reports of 'how one has felt yesterday'. Reports on recent feelings are probably less vulnerable to desirability distortion, because it is less embarrassing to say one has felt down lately, than to admit one's life-as-a-whole is unsatisfactory. Recent feelings are also more difficult to deny; defense mechanisms have a better chance in the less palpable evaluation of life-as-a-whole. As a result we should see much divergence between reported happiness and affect level as measured by the balance of positive and negative affects in the previous day. For the same reason there will also be divergence between happiness and affect on the individual level. Desirability pressures produce uniformly high reports of happiness, whereas reports of affect remain closer to reality and are more variable. This must manifest in small correlations between reports of these happiness variants; particularly in countries that cherish happiness, such as the USA.

The World Database of Happiness contains data on 130 nations in which both overall lifesatisfaction and affect balance have been assessed. The measure of affect balance is based on responses to 14 questions about experiences during the previous day, such as 'Did you feel well rested yesterday? Yes or no?' Average scores on both measures of happiness appear to be strongly correlated $r=+.52$. Yet the correlation is not perfect, there are some deviant cases in African countries, where affect is high relative to life-satisfaction and in former communist Eastern European countries where affect is low relative to life satisfaction. Life-satisfaction and affect balance are more in line in Asia, where both fall in the middle range and in Western Europe, where both are high (Rojas \& Veenhoven, 2012). The USA does not stand out as a case where high self-reports of overall happiness go together with low affect balance score.

\footnotetext{
${ }^{9}$ Findings on happiness and value climate in nations: prevalence of hedonic values (subject code N4.11.2) World Database of Happiness (Veenhoven 2012g).
} 
All things considered, the observed differences in average happiness across nations are unlikely to be much influenced by desirability bias.

\subsubsection{Differences due to response style?}

The third claim holds that in collectivistic societies, such as Japan, people will tend to present themselves as 'average' citizens. Therefore, they will respond modestly and be apt to choose the midpoint of the response scale. This will lead to relatively low scores, because happiness is typically above neutral. By choosing the (neutral) midpoint of the scale, collectivistic people will avow themselves less happy than they are (Iljima, 1982). In individualistic societies, people are seen to define themselves on difference with others, or orientate on internal cues and will therefore more often tick the higher end of the scale.

If this claim is true, average happiness must be lower in collectivistic countries than in individualistic ones. This is indeed the case (Veenhoven, 1999), but that does not necessarily signify cultural measurement bias, since the difference can also be due to differences in livability of cultures, collectivism fitting human nature less well. Another implication would seem that the dispersion of happiness in a country, as apparent in standard deviation, must be smaller in collectivistic countries than in individualistic ones, collectivists tending to flock together. Further happiness must be closer to the midpoint of the scale in collectivistic countries than in individualistic ones, irrespective of the average.

Greater dispersion of happiness in collectivistic nations, rather than less. Inequality of happiness among citizens in a nation can be measured using the standard deviation (Kalmijn \& Veenhoven, 2005), which appears to be to be smaller the more individualized the country ( $\mathrm{r}=$ .78). This contradicts the prediction of collectivists flocking together.

No particular concentration in middle categories. As mentioned above, Iljima suggests that the Japanese tend to choose the midpoint of the scale. There is some truth in this observation: for the 2000 World Value Survey 37\% of the Japanese responses are in the categories 4, 5 and 6. Yet this is less than half of the population and about as many of the Japanese scored 8, 9 or 10 $(35 \%)$. A similar pattern is observed in South Korea. The data do not show a concentration in the middle comparable to the concentration at the top of the distribution as we see in western nations. The distribution is just flatter and reveals greater percentages of very unhappy respondents. ${ }^{10}$

In sum, the lower happiness in collectivistic countries cannot be disposed as a matter of response tendency.

\subsubsection{Differences a matter of familiarity with the concept?}

The last claim to be checked is that happiness is a typical Western concept, that is, because people in non-western societies are less familiar with the concept, they will respond more erratically, which will result in greater dispersion and a lower average. If unfamiliarity is indeed involved we can expect more 'don't know' and 'no answer' responses in non-western societies: particularly on questions which use the word 'happiness'.

Data are presented in Table 6 (below). Again the prediction is refuted by the data. Nonresponse to questions about appreciation of life is generally low and not lower in non-western nations than in western ones. So, it can be concluded that the observed differences in average

\footnotetext{
10 There is a more pronounced tendency among East Asians to select the middle category in responses to Cantril's ladder question (Helliwell \& Wang 2012) This question, mentioned in Box 1, invites to a rating of one's life between the best and the worst possible.
} 
happiness across nations cannot be explained by variation in comprehensibility of survey questions on this matter.

Table 6. 'Don't Know' response to survey questions about happiness

\begin{tabular}{lcc}
\hline Nation & Life-satisfaction & Happiness \\
\hline USA & $0.2 \%$ & $0.8 \%$ \\
Zimbabwe & $0.3 \%$ & $0.2 \%$ \\
China & $0.5 \%$ & $1.0 \%$ \\
France & $0.6 \%$ & $0.8 \%$ \\
Russia & $1.4 \%$ & $4.5 \%$ \\
India & $2.7 \%$ & $1.1 \%$ \\
Average in 84 nations & $0.8 \%$ & $1.5 \%$ \\
\hline
\end{tabular}

Source: World Values Surveys, life-satisfaction item, average waves 1 to 4.

\subsection{General validity checks}

The total validity of happiness can be assessed against its correspondence with other indicators of wellbeing. This is called external validity testing. There are two ways to do that.

One is to assess correspondence with other indicators of enjoyment of life in nations, such as incidence of depression and suicide. This is called congruent validity. In this context it also makes sense to compare with indicators of physical thriving, such as longevity. The second is to assess correspondence of happiness with conditions that are likely to be conducive to it. This is called concurrent validity. In this case we consider the link between external chances for a good life with the internal outcomes of life.

\subsubsection{Congruent validity tests 1: Correspondence with other indicators of wellbeing}

Happiness is only one indicator of the degree to which people flourish in a society. Other indicators are incidence of depression and suicide and longevity.

Less depression in happier nations. If happiness is a relevant indicator of livability of society, we can expect a negative correlation between average happiness in nations and the incidence of depression. This appears to be the case. Van Hemert et al. (2002) compared average happiness and scores on the Beck Depression Inventory (BDI) in 29 nations and found that BDI scores were negatively correlated with subjective wellbeing and other happiness-related variables $(\mathrm{r}=$ -.42). They conclude that depression has the same meaning at individual and country level and that depression is an adequate measure of (a lack of) subjective wellbeing at country level.

Less suicide in happier nations. If self-reports of happiness adequately reflect enjoyment of life in a nation, we can also expect a negative correlation with suicide rates. This also appears to be the case. The correlation in the set of 52 nations on which data is available is -.40. This relation is discussed in more detail in Helliwell (2007). 
Longer life in happier nations. Subjective enjoyment of life is likely to correspond with actual thriving and this must be reflected in longevity. There is a strong correlation: $r=+.50$. Likewise average happiness in nations is also linked to self-rated health, $r=+.60$.

\subsubsection{Concurrent validity tests 2: Correspondence with livability of nations}

Concurrent validity testing is assessing correspondence with phenomena of another kind, likely to be causally related. In this case we can compare average happiness with indicators of the quality of society, such as material affluence and good governance. Reported happiness is likely to be higher in nations that provide good living conditions than in nations that do not. ${ }^{11}$

Above in section 3.3 we have already considered the statistical association between happiness and societal qualities, which together explain $75 \%$ of the differences in reported happiness in 148 nations. See Table 3. So there is a considerable correspondence! Still, not everything deemed desirable appears to be correlated with happiness. Remember the noncorrelation with income-inequality.

\subsection{How much measurement bias?}

Any measurement involves bias and this measurement of happiness in nations will be no exception. So the question is not whether measurement bias is involved, but rather how much. The above analysis of societal correlates provides a cue.

As we have in Table 3, this handful of societal characteristics explains $75 \%$ of the observed differences in happiness. The variables involved are of an objective nature and their measurement is unlikely to be affected by the distortions presumed to be involved in the measurement of happiness. As such this high degree of explained variance marks that something solid is being measured and that the bias in the measurement of happiness can be no more than $25 \%$. Following this line of reasoning we must also acknowledge that the set of variables involved is far from complete. We have to make do with variables on which international statistics are available and we lack such data on potentially important things such as the quality of friendships in nations. If we had more data we could probably explain some $90 \%$ of the cross-national differences in happiness. What is more: the measurement of societal characteristics is not free of error either, not even the measurement of income per head and this also detracts from the explained variance.

Together, this means that the bias in the measurement of happiness is small at best, probably about $5 \%$.

\section{Meaning of the differences}

There are also misgivings about cultural variation in the meaning of happiness. It is argued that happiness is a mere idea and that the observed differences are therefore of little consequence. The Danes may be more positive about their life than the Russians, but they evaluate their life in a different way and the outcomes are therefore not really comparable. This critique roots in a cognitive theory of happiness. Below I will take a closer look at this theory (5.1) and then

\footnotetext{
${ }^{11}$ There is some circularity in such a test. We measure happiness in nations to identify societal conditions that contribute to happiness, because we do not trust current assumptions. Now we are about to validate our measure of happiness using these distrusted matters. Still, it is worth knowing whether these indicators correspond or not. Common beliefs are not held without any ground. So there must at least be some correspondence. If we do not find any relationship, there is clearly something wrong with one or both. If, however, we find a strong statistical relationship, we can be fairly sure that both indicators do reflect livability.
} 
present some evidence against it (5.2). Next I will outline the alternative theory that happiness signals the gratification of universal human needs.

\subsection{The theory that happiness is culturally relative}

In this view, happiness is regarded as a social construction, comparable to notions like 'beauty' and 'fairness'. In this line it is assumed that happiness depends on shared notions about life and that these collective notions frame individual appraisals.

One of the ways this is assumed to work is individuals seeing the glass as half full or half empty, optimistic cultures tending to highlight the positive aspects of life, while pessimistic cultures emphasize its shortcomings. Americans have been mentioned as an example of the former view and the French of the latter, e.g. by Ostroot \& Snyder (1985). In this line Inglehart (1990: 30) has suggested that happiness is lower in France than in the US, because life was harder in France for earlier generations, and this is echoed in a more pessimistic outlook on life today.

Another cognitive mechanism assumed to gear happiness is comparison with shared notions of the good life. In this view, happiness is the gap between perceptions of life-as-it-is with notions of how-life-should-be. In this line it is commonly argued that the advertising industry reduces our happiness, because it fosters dreams of a life that is out of reach for the common man (Layard, 2005). In this line the low level of reported happiness in poor countries has also been explained as a result of exposure to western life-style. Critics of western society see that as 'false consciousness' and assume that poor Africans actually live better than they believe.

An additional mechanism that has been mentioned is that we see ourselves typically though the eyes of others and hence also judge our happiness through their eyes. In this view, happiness is a 'reflected appraisal'. We will be positive about our life when people around us deem us to be well off and negative when others see us as losers. In this vein the lower happiness in poor countries could be explained as the result of labeling: because Africans see themselves lagging behind in the eyes of Europeans, they would define themselves as unhappy, in spite of the advantages of their authentic way of life.

The constructionist view implies that there is little value to happiness, happiness being a mere idea. Since notions about the good life vary across time and culture, happiness is also seen to be culturally relative. A life that is deemed perfect in one culture may be seen to be a failure in another value system.

\subsection{Some tests of the cultural relativity thesis}

It is beyond doubt that shared notions frame much of our appraisals, yet this is not to say that all awareness is socially constructed. We need no shared notions to experience pain or hunger; culture at best modifies our reflection on these experiences somewhat. Our understanding draws also on external stimuli and on inner signals. The question thus is: How does this work in the case of happiness?

The reality value of this view cannot be tested as such, because the human mind is still a black box. Yet we can check its aptness indirectly, when we consider the implications of the theory that happiness is a mere social construct. 


\subsubsection{Pattern of happiness not culture specific}

One implication is that conditions for happiness will be variable across cultures. If happiness is a culture-specific construct, its determinants will also be culturally specific. Hence empirical studies on correlates of happiness must show considerable cultural variation and hardly any universal pattern. Yet the available data show otherwise.

Similar conditions across nations. Comparison of average happiness across nations reveals a common pattern. Happiness is systematically higher in nations that provide a decent material standard of living, freedom, equality, solidarity and justice. Remember Table 3 and in particular the fact that these societal conditions explain together no less than $75 \%$ of the observed variation in average happiness across nations.

Similar correlations within nations. There are also differences in individual happiness within nations. In a happy country like Denmark $5 \%$ of the people still rate 5 or lower on the $0-10$ scale and in an unhappy country like Zimbabwe some 13\% score 8 or higher. Are the reasons for high and low scores similar across nations? Below, I consider some living conditions for which cross-national data are available.

Freedom. Not only is average happiness higher in free countries, but within countries individuals are also happier the more control they have over their life. This appears among other things in strong correlations between personal happiness and perceived freedom and control all over the world. ${ }^{12}$

Social rank. People are typically happier on the upper steps of the social ladder than at the bottom. This appears in findings on relative income position, ${ }^{13}$ occupational prestige, ${ }^{14}$ subjective class identification ${ }^{15}$ and indexes of socio-economic status ${ }^{16}$. The differences tend to be bigger at the lower end of the hierarchy. Though the correlations with happiness differ in size, they are positive all over the world. This finding fits the view that we have an innate need for social respect. Like other group animals we are hardwired to avoid a bottom position.

Marriage. Adults are typically happier when living with a spouse then when single. The difference is around half a point on a 0-10 scale and is largely independent of income, gender and age. Again, the size of the difference varies somewhat across time and nations but the pattern is clearly universal. ${ }^{17}$ This finding fits the view that we are social animals, hardwired to form pairs.

Personality. Cross-national research on the relationship between happiness and personality is limited as yet, but the available data suggest that extraverted people tend to be happier ${ }^{18}$ across a variety of nations (Lucas et al., 2000) and that neurotics tend to be less happy in all

\footnotetext{
12 World Database of Happiness, Correlational Findings (Veenhoven 2012g), subject section ‘Personality, Inner Locus of control' (P4.58). For a recent cross national study see: Verme (2008).

${ }^{13}$ World Database of Happiness, Correlational Findings (Veenhoven 2012g), subject section 'Current income' (1.2) For a recent cross-national comparison see: Ball \& Chernova (2008).

${ }^{14}$ World Database of Happiness, Correlational Findings (Veenhoven 2012g), subject section 'Current Occupational level' (O1.3.1).

${ }^{15}$ World Database of Happiness, Correlational Findings (Veenhoven 2012g), subject section 'Subjective Social Rank' (S9.2.2).

${ }^{16}$ World Database of Happiness, Correlational Findings (Veenhoven 2012g), subject section 'Objective Social Status' (S9.2.1).

17 World Database of Happiness, Correlational Findings (Veenhoven 2012g), subject 'Marital status' (M2.1). See also Diener et al. (2000).

${ }^{18}$ Schimmack et al. (2002) found that the link between Extraversion and Hedonic Level of Affect is more universal than the link between Extraversion and Overall Happiness and suggest that the influence of personality on the emotional component of happiness is pan-cultural, whereas the influence of personality on the cognitive component of happiness is more moderated by culture.
} 
cultures. Once more there is difference in the size of the effects. For instance the effect of selfesteem appears to be stronger in individualistic cultures than in collectivistic cultures (Oishi et al., 1999). Still, the direction is the same everywhere.

This is not to say that all conditions for happiness are universal. One notable exception is 'education'. Although there is a correlation between average happiness and level of education in countries, the most highly educated individuals are not always happier. Correlations between happiness and education vary from -.08 to +.27 . The correlation is typically much reduced when controlled for income or occupational status. ${ }^{19}$

\subsubsection{Average happiness is stable over time, but responsive to major events}

A second implication is that happiness must be variable over time. If happiness depends on shared notions of the good life, it will vary with fads about that matter and this is likely to be reflected in erratic movements in average happiness in nations, comparable to changes in political preferences and tastes for music. Yet again this not what the data show. Average happiness appears to be very stable over time, at least in western nations, where happiness has risen slightly without many fluctuations over the last 40 years (Veenhoven, 2012e).

This is not to say that average happiness in nations is immutable. Happiness is rising gradually in most nations of the present-day world, and in particular in successfully developing nations (Veenhoven \& Hagerty, 2006). Happiness is also responsive to major events. Average happiness dropped by more than one point in Russia in the late 1990s after the ruble crisis. Evidently, this drop cannot be attributed to a sudden change in collective outlook on life.

\subsubsection{Happiness of migrants closer to country of settlement than to country of origin}

If the appraisal of life is largely determined by socialized outlook, we can expect that migrants judge life differently from natives. Though migrants live in the same society, they will evaluate it differently, because they look at life through differently cultured eyes. In this context, one can expects that: One: average happiness of migrants will be closer to the average level in their country-of-origin than to the average in the country-of-settlement; Two: that this will be especially true for recent migrants; and Three: that among migrants of different origins in a country, the rank order of happiness will be similar to the rank order of happiness among their respective countries-of-origin.

Elsewhere I have tested these predictions in two countries in the 1980s: Australia and West Germany. These countries host a sizable number of new-comers: Australia, migrants from Western Europe and Mediterranean countries; and Germany, Mediterranean migrants. In both countries survey studies had assessed happiness in samples that involved sizable numbers of migrants (Veenhoven, 1994).

Average happiness of migrants close to average in country of settlement. Prediction one is clearly defied by the data. The happiness of migrants is typically closer to the average in the countryof-settlement, than to the average in the country-of-origin. Migrants from Mediterranean countries are typically happier in Australia and Germany than their relatives at home are. All were first-generation migrants, whose pre-adult socialization took place in the country of origin. Hence, if they had been brought up with a gloomy outlook, they have apparently lost that cultural heritage quite quickly.

\footnotetext{
${ }^{19}$ World Database of Happiness, States of Nations (Veenhoven 2012f), variable r_LS_Education_1990.
} 
Second generation hardly closer. Prediction two is a specification of the first one and is thus also largely disproved. Still, we can look at the minor differences between happiness of migrants and the general public in the country of settlement. In Australia this difference is little greater among fresh migrants than among first-generation veterans. In Germany the prediction is confirmed; second-generation migrants are closer to the average German than are their firstgeneration parents. Obviously this can also be the result of better adjustment to German society.

Rank-order of happiness in countries of origin not reproduced. Prediction three is also not supported. In only half the cases do we see that the rank order of happiness among migrants more or less reflects the differences among mother-countries. This is for instance the case in the USA, where migrants from Northern Europe tend to be happier than migrants from Southern Europe, which reflects the difference in happiness between the North and south of Europe (Beals, 1985). Yet in Australia migrants from Italy appeared to be equally as happy as the average Australian, in spite of the fact that average happiness in Italy is much lower (Veenhoven, 1994: Scheme 10).

\subsubsection{Happiness is closely linked to human thriving}

A third implication is that happiness is of little consequence. If happiness is sheer cognitive spin, based on fashionable ideas, it will not matter much whether it pans out positively or negatively. Happiness is then a petty appraisal, such as a person's preference for one kind of wallpaper or another; nice in itself but of no consequence for anything more than that.

Once more, this appears not to be the case. Happiness appears to go hand in hand with objective thriving. Follow-up studies have shown that happiness is a strong predictor of physical health and longevity, both at the individual level and at the societal level (e.g. Danner et al., 2000; Veenhoven, 2008).

Together, these findings do not support the theory that happiness is a mere making of the mind.

Note that these findings concern happiness-as-such, and not opinions about what adds to happiness. Happiness-as-such is something that we experience ourselves and which we can appraise without the help of others. Though we know how we feel, we often do not know why and in attributing grounds for our wellbeing we draw more on shared views. In this respect happiness is comparable to a headache: a headache-as-such is not a social construction, it is an autonomous signal from the body. Yet our interpretations of what gives us a headache depend very much on hearsay.

\subsection{The theory that happiness signals need-gratification}

An alternative view holds that we do not 'calculate' happiness, but rather 'infer' it, the typical heuristic being "I feel good most of the time, hence I must be happy" (Schwartz \& Strack, 1991)

It would seem that this inference is geared by our most salient affective experiences and that these are typically intense affects. This view is common in fiction. Yet research using the Experience Sampling Method shows that it is rather the frequency of affective experience that matters more than its intensity (Diener et al., 1991).

How do we assess the relative frequency of positive and negative affects? The cognitive view on affect procession suggests that we compute an affect balance in some way, using estimates of frequency and duration. A competing view is that this occurs automatically and that the balance reflects in mood. In this view mood is an affective meta-signal that, contrary to feelings and emotions, is not linked to specific objects. Emotions denote an affective reaction to 
something and prepare the organism to respond, while a negative mood signals that there may be something wrong and urges us to find out what that is. This latter process seems to be the most common; conscious computation of affect balance is rather the exception and typically limited to situations in which people do not trust their mood.

\subsubsection{Gratification of needs}

Why do we feel good or bad at all? Probably because that signals how well we are doing. Affects are an integral part of our adaptive repertoire and seem to be linked to the gratification of human needs. 'Needs' are vital requirements for survival, such as eating, bonding and exercise. Nature seems to have safeguarded the gratification of these needs with affective signals such as hunger, love and zest. In this view a positive mood signals that all needs are sufficiently met at the moment. 'Needs' in this theory should not be equated with 'wants' in the above discussion of cognitive theories. Needs are inborn and universal, while 'wants' are acquired and can be variable across cultures. Wants can at best concur, more or less, with needs.

\subsubsection{Function of happiness}

In this view, negative and positive moods function as red and green lights on the human machine, indicating either that there is something wrong or that all systems are functioning properly. If so, this is likely to have behavioral consequences, a negative mood urging caution and a positive mood encouraging action. ${ }^{20}$ This is what Fredrickson's (2004) 'broaden and built' theory is about.

This theory also makes sense in an evolutionary perspective. It is likely that evolution has developed ways of monitoring needs gratification, in particular in organisms that can make choices. It is unlikely that rational thinking is the main path of monitoring, since rational thinking developed late in our evolution and animals can apparently do without it. It is quite likely that adaptation is guided by affective signals in the first place and that all higher animals can feel more or less well. It is unlikely that humans are an exception to this rule. Our ability to think rationally has been added to an existing affect system and has not replaced it. This can be seen in the structure of the human brain, where the affect system is located in the older parts that we have in common with other animals. The ratio is situated in the neo-cortex, a part of the brain that is typical to humankind and to a lesser degree to the great apes. This 'need theory' of happiness is summarized in Figure 2 (below). The theory implies that happiness is a universal phenomenon and as such can be compared well across nations. In this view differences in average happiness in nations denote variation in societal effectiveness in meeting human needs. I have discussed this theory in more detail elsewhere (Veenhoven, 1995; 2006; 2010a; 2010b).

\section{Conclusion}

Average self-reported happiness varies considerably across nations. These differences cannot be denounced as mere measurement bias, nor can they be explained as a result of cultural differences in the evaluation of life. The observed differences in happiness rather denote that not all societies meet universal human needs equally well.

\footnotetext{
${ }^{20}$ This is not to say that negative affect inhibits all action, especially not in the case of fear and anger. Still, positive affects tend to be more activating than negative affects are, on average.
} 
Figure 2. Need theory of happiness

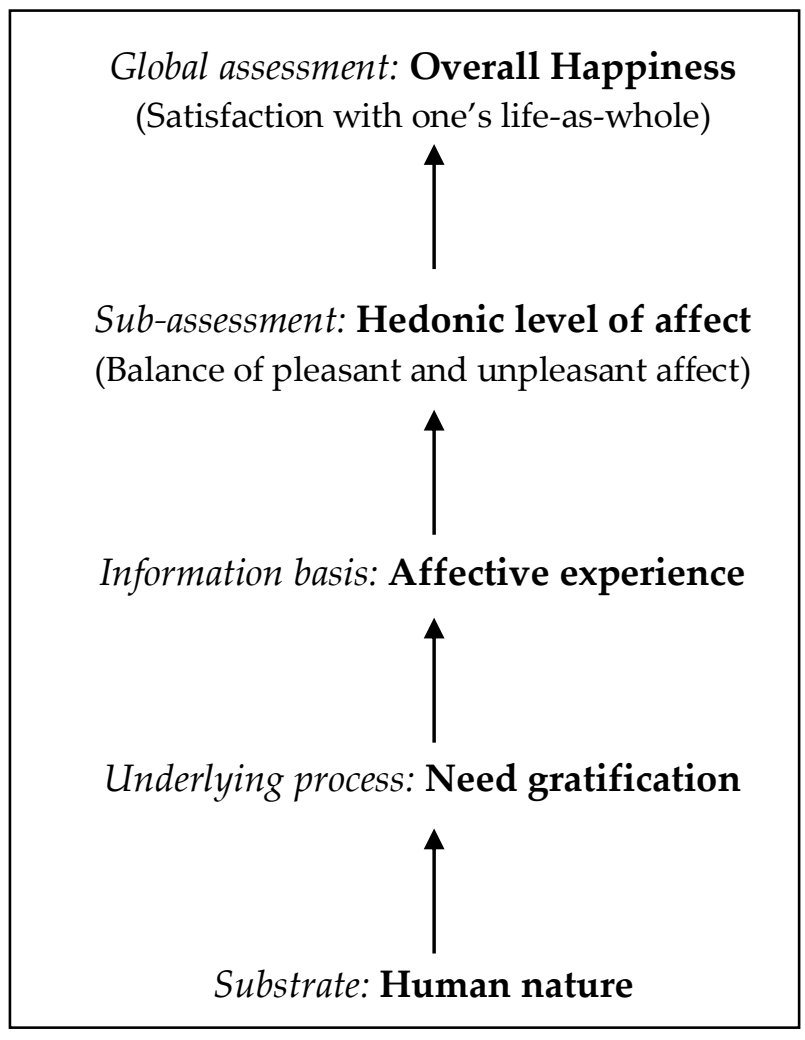

Source: Veenhoven (2006).

\section{Author}

Ruut Veenhoven

Erasmus University, The Netherlands \& North-West University, South Africa veenhoven@fsw.eur.nl

\section{Publishing Timeline}

Received 13 March 2012

Accepted 27 August 2012

Published 13 December 2012

\section{References}

Andrews, F. M. \& Withey, S. B. (1976). Social indicators of well-being. New York, U.S.A., Plenum Press.

Ball, R. E. \& Chernova, K. (2008). Absolute Income, Relative Income, and Happiness. Social Indicators Research, 88: 497-529. http://dx.doi.org/10.1007/s11205-007-9217-0

Beals, J. (1985). Generational differences in wellbeing for two European groups. PhD dissertation, University of Michigan, USA.

Blishen, B. R. \& Atkinson, T. H. (1980). Anglophone and Francophone Perceptions of the Quality of Life in Canada. In Szalai, A. \& Andrews, F., (Eds.) The Quality of Life, Comparative Studies. Sage, London, 25-40.

Cantril, H. (1965). The pattern of human concern. New Brunswick, U.S.A., Rutgers University Press.

Danner, D. D., Friessen, W. V., \& Snowdon, D. A. (2001). Positive Emotions in Early Life and Longevity: Findings from the Nun Study. Journal of Personality and Social Psychology, 80: 804-813. http://dx.doi.org/10.1037/0022-3514.80.5.804

Diener, E. (1994). Assessing Subjective Well-Being: Progress and Opportunities. Social Indicators Research, 31: 103-157. http://dx.doi.org/10.1007/BF01207052 
Diener, E., Emmons, R. A., Griffin, S., \& Larsen, R. J. (1985). The Satisfaction with Life Scale. Journal of Personality Assessment, 49: 71-75. http://dx.doi.org/10.1207/s15327752jpa4901_13

Diener, E., Pavot, W. \& Sandvik, E. (1991). Happiness Is the Frequency, Not Intensity of Positive and Negative Affect. In Strack, F., Argyle, M., \& Schwartz, N. (Eds.) Subjective wellbeing: An interdisciplinary perspective. Pergamon, London.

Diener, E., Gohm, C. L., Oishi, S., \& Suh, E. M. (2000). Similarity of the Relation Between Marital Status and Subjective Well-Being across Cultures. Journal of Cross-Cultural Psychology, 31: 419-436.

http://dx.doi.org/10.1177/0022022100031004001

Eurobarometer Survey (EBS): http://ec.europa.eu/public_opinion/index_en.htm

European Social Survey (ESS): http://www.europeansocialsurvey.org

Easterlin, R. A. (1974). Does Economic Growth Improve the Human Lot? Some Empirical Evidence. In David, P. A. \& Melvin, W. R. (Eds.) Nations and households in economic growth. Academic Press, New York, USA, 89-125.

Fredrickson, B. L. (2004). The Broaden-and-Build Theory of Positive Emotions. Philosophical Transactions, Biological Sciences, 359: 1367-1377. http://dx.doi.org/10.1098/rstb.2004.1512

Gallup, G. H. (1976). Human Needs and Satisfactions: A Global Survey. Public Opinion Quarterly, 40: 459467. http://dx.doi.org/10.1086/268332

Helliwell, J. F. (2007). Well-Being and Social Capital: Does Suicide Pose a Puzzle? Social Indicators Research, 81: 455-496. http://dx.doi.org/10.1007/s11205-006-0022-y

Helliwell, J. F. \& Wang, S. (2012). The State of World Happiness. In Helliwell, J. F., Layard, R., \& Sachs, J. (Eds.) The world happiness report, Chapter 2, Earth Institute, Washington, USA.

Iijima, K. (1982). The Feelings of Satisfaction and Happiness of the Japanese and Other People. Nippon Research Center, Japan.

Inglehart, R. (1990). Culture shift in advanced industrial society. Princeton University Press, Princeton, USA.

Kalmijn, W. M. \& Veenhoven, R. (2005). Measuring Inequality of Happiness in Nations: In Search of Proper Statistics. Journal of Happiness Studies, 6: 357-396. http://dx.doi.org/10.1007/s10902-005-8855-7

Layard, R. (2005). Happiness, lessons of a new science. Penguin, London, UK.

Lucas, R. E., Diener, E., \& Suh, E. M. (1996). Discriminant Validity of Well-Being Measures. Journal of Personality and Social Psychology, 71: 616-628. http://dx.doi.org/10.1037/0022-3514.71.3.616

Lucas, R. E. \& Gohm, C. L. (2000). Age and Sex Differences in Subjective Well-Being across Cultures. In Diener, E. \& Suh, E. M. (Eds.) Culture and subjective well-being. MIT Press, Cambridge USA, 291-317.

Neugarten, B. L., Havinghurst, R. J., \& Tobin, S. S. (1961). The Measurement of Life Satisfaction. Journal of Gerontology, 16: 134-143.

Oishi, S., Diener, E., Lucas, R. E., \& Suh, E. M. (1999). Cross-Cultural Variations in Predictors of Life Satisfaction: Perpectives from Needs and Values. Personality and Social Psychology, 25: 980-990. http://dx.doi.org/10.1177/01461672992511006

Ostroot, N \& Snyder, W. W. (1985). Measuring Cultural Bias in a Cross-National Study. Social Indicators Research, 17: 243-251. http://dx.doi.org/10.1007/BF00319313

Rojas, M. \& Veenhoven, R. (2012). Cognition and Affect in the Appraisal of Life. Social Indicators Research (in press).

Schimmack, U., Ahadi, S., Dzokoto, V., Oishi, S., \& Radhakrishnan, P (2002). Culture, Personality, and Subjective Well-Being: Integrating Process Models of Life Satisfaction. Journal of Personality and Social Psychology, 82: 582-593. http://dx.doi.org/10.1037/0022-3514.82.4.582

Schwarz, N. \& Strack, N. (1991). Evaluating one's life: A judgment model of subjective well-being. In Strack, F., Argyle, M., \& Schwarz, N. (Eds.) Subjective wellbeing. Pergamon, London UK, 27-48.

Van Hemert, D. A., Poortinga, Y. H., \& van de Vijver, F. J. (2002). The Beck Depression Inventory as a Measure of Subjective Well-Being: A Cross-National Study. Journal of Happiness Studies, 3: 257-286. http://dx.doi.org/10.1023/A:1020601806080

Veenhoven, R. (1984). Conditions of happiness. Kluwer (now Springer), Dordrecht, Netherlands

Veenhoven, R. (1994). Is happiness a Trait? Social Indicators Research, 32: 101-160.

http://dx.doi.org/10.1007/BF01078732 
Veenhoven, R. (1995). The Cross-Cultural Pattern of Happiness: Test of Predictions Implied in Three Theories of Happiness. Social Indicators Research, 34: 33-68. http://dx.doi.org/10.1007/BF01078967

Veenhoven, R. (1999). Quality-of-Life in Individualistic Society. Social Indicators Research, 48: 157-186. http://dx.doi.org/10.1023/A:1006923418502

Veenhoven, R. (2000). The Four Qualities of Life. Journal of Happiness Studies, 1: 1-39. http://dx.doi.org/10.1023/A:1010072010360

Veenhoven, R (2005). Is Life Getting Better? How Long and Happy Do People Live in Modern Society? European Psychologist (special section on 'Human development and Well-being'), 10: 330-343.

Veenhoven, R. (2006). How Do We Assess How Happy We Are? Tenets, Implications and Tenability of Three Theories. In Dutt, A. K. \& Radcliff, B. (Eds.) Happiness, economics and politics: Towards a multidisciplinary approach. Edward Elger Publishers, Cheltenham UK, Chapter 3, 45-69.

Veenhoven, R. (2008). Healthy Happiness: Effects of Happiness on Physical Health and Consequences for Preventive Healthcare. Journal of Happiness Studies, 9: 449-464.

Veenhoven, R. (2010a). Life is Getting Better: Societal Evolution and Fit with Human Nature. Social Indicators Research, 97: 105-122. http://dx.doi.org/10.1007/s11205-009-9556-0

Veenhoven, R. (2010b). How Universal is Happiness? (Chapter 11) In Diener, E., Helliwell, J. F., \& Kahneman, D. (Eds.) International differences in well-being. Oxford University Press, New York, 328350 .

Veenhoven, R, (2012a). World database of happiness: Continuous register of scientific research on subjective appreciation of life. Erasmus University Rotterdam, Netherlands.

http://worlddatabaseofhappiness.eur.nl

Veenhoven, R. (2012b). Happiness in Nations. World database of happiness. Erasmus University Rotterdam, Netherlands. http://worlddatabaseofhappiness.eur.nl/hap_nat/nat_fp.php

Veenhoven, R. (2012c). Bibliography of Happiness. (Section F ‘Happiness and Society') World database of happiness. Erasmus University Rotterdam, Netherlands. http://worlddatabaseofhappiness.eur.nl/hap_bib/bib_fp.php

Veenhoven, R. (2012d). Average happiness in 149 nations 2000-2009: How much people enjoy their lifeas-a-whole on scale 0 to 10. World database of happiness. Erasmus University Rotterdam, Netherlands. http://worlddatabaseofhappiness.eur.nl/hap_nat/findingreports/RankReport_AverageHappiness.ph $\mathrm{p}$

Veenhoven, R. (2012e). Trend average happiness in nations 1946-2010: How much people like the life they live. World database of happiness. Erasmus University Rotterdam, Netherlands. http://worlddatabaseofhappiness.eur.nl/hap_nat/findingreports/TrendReport_AverageHappiness.pd f

Veenhoven, R. (2012f). States of nations: Dataset to be used for the cross-national analysis of happiness. World database of happiness. Erasmus University Rotterdam, Netherlands http://worlddatabaseofhappiness.eur.nl/statnat/statnat_fp.htm

Veenhoven, R. (2012g). Correlates of Happiness. World database of happiness. Erasmus University Rotterdam, Netherlands http://worlddatabaseofhappiness.eur.nl/hap_cor/cor_fp.htm

Veenhoven, R. \& Hagerty, M. (2006). Rising happiness in nations, 1946-2004. A reply to Easterlin. Social Indicators Research, 79: 421-436. http://dx.doi.org/10.1007/s11205-005-5074-x

Verme, P. (2009). Happiness, Freedom and Control. Journal of Economic Behavior E Organization, 71: 146161. http://dx.doi.org/10.1016/j.jebo.2009.04.008

World Values Survey (WVS); http://worldvaluessurvey.org 